doublet at $516 \mathrm{c} / \mathrm{s}$ showed the expected fine structure $\left(J_{5-4} \approx 8 \mathrm{c} / \mathrm{s}\right)$.

Since all the immunochemically significant fluoresceins (amines, isocyanates and isothiocyanates) are derived from the nitrofluoresccins by straightforward reactions, the positions of substitution are now known: the I series is 5 -substituted, and isomer II compounds are substituted at $\mathrm{C}_{6}$. It is noteworthy that infra-red data led Borek ${ }^{2}$ to suggest structural assignments opposite to those which nuclear magnetic resonance so clearly imposes.

We thank Dr. Roger M. McKinney, who supplied the nitrofluorescein derivatives.

Biology/Chemistry Section,

Howard S. CoREY, JUn.* Frederick C. Churchill, II

Technology Branch,

Communicable Disease Center,

Public Health Service,

Savannah, Georgia.

* Present address: Lederle Laboratories Division, American Cyanamid Co. Pearl River, New York.

' Coons, A. H., and Kaplan, M. H., J. Exp. Med., 91, 1 (1950).

2 Borek, F., J. Org. Chem., 26, 1292 (1961).

sople, J. A., Schneider, W. G., and Bernstein, H. J., High-resolution Nuclear

Magnetic Resonance, 259 (McGraw-Hill, New York, 1959).

\section{Pulsed Radiolysis of Gases: Direct Observation of 's Carbon Atoms in Carbon Dioxide, Carbon Monoxide and Methane}

THE reactions of free carbon atoms with both organic and inorganic molecules have been extensively studied in the gas phase ${ }^{1-4}$. In their investigations of the reactions of ${ }^{11} \mathrm{C}$-atoms in organic systems, Wolfgang et al. ${ }^{2}$ obtained a thorough knowledge of the products and were thus able to develop a general mechanism for carbon atom reactions, but little is known about the specific rates of these reactions and about the electronic state of a reacting carbon atom.

By means of pulsed radiolysis ${ }^{5}$, we have been able to observe the optical absorption of a transient species in carbon dioxide irradiated by electrons. This spectrum is assigned to a carbon atom in the ${ }^{1} S$ state, and the same absorption has been seen in irradiated carbon monoxide and methane.

The pulsed $250 \mathrm{kV}$ electron source used in this work will be described in detail elsewhere. It produces single pulses about $0.2 \mu \mathrm{sec}$ in duration. Gas samples free from air were irradiated at pressures which allowed an energy deposition in the gas of about $6 \times 10^{18} \mathrm{eV} /$ pulse. A stainless steel irradiation cell (capacity 4.6 l.) was equipped with an internal mirror system based on the White design ${ }^{6}$ and was used with path lengths of up to $13 \mathrm{~m}$. The half width of the analytical flash was about $2 \mu \mathrm{sec}$. Spectra were recorded with the aid of a Hilger medium spectrograph using Ilford $H P 3$ plates. Lifetimes of the transient absorption were determined from optical density measurements made at different intervals of time after the electron pulse.

All gases were purified by normal vacuum line techniquos, and methane was further purified by passage over freshly deposited getter (Mischmetal). The total dose received by any gas sample did not exceed $5 \times 10^{19} \mathrm{cV}$.

For the three gases studied only one transient absorption was observed in the spectral range $2300 \AA-4700 \AA$. In each case it was found at $2478 \AA$ (sec Fig. 1) and appeared as a single sharp line with no evidence of struc. ture. The wavelength calibration of the spectrograph was confirmed by means of a carbon arc, the persistent spectral line from which corresponded exactly to the absorption. The line is therefore assigned to the $\left({ }^{1} P \leftarrow{ }^{1} S\right)$ transition of the carbon atom.

The half-life of the ${ }^{1} S$ carbon atom produced in different systems is shown in Table 1 . In pure methane the absorption was only visible immediately following the

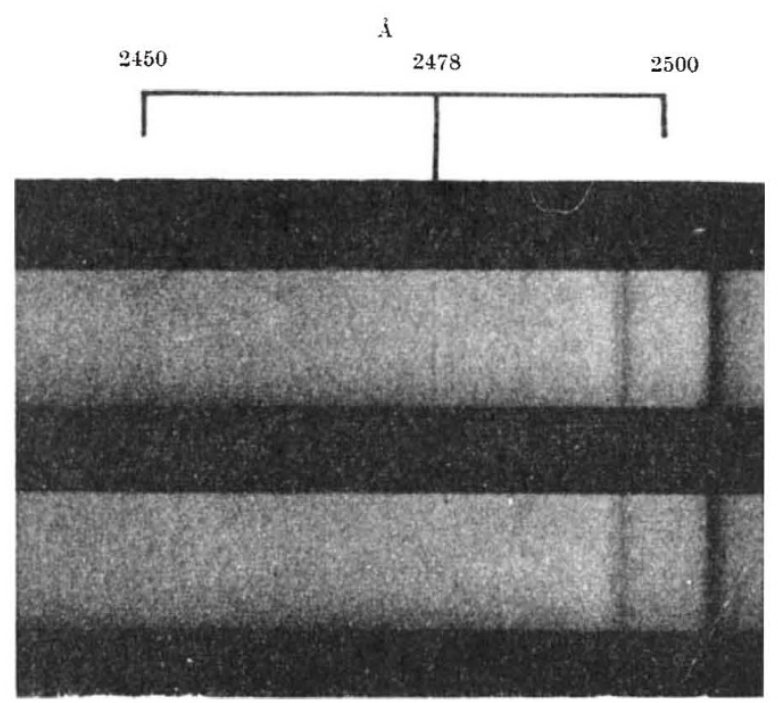

Fig. 1. The transient absorption spectrum caused by $C\left({ }^{1} S\right)$ at $2478 \mathrm{~A}$ in the upper trace was photographed $1 \mu \mathrm{sec}$ after the electron pulse. The pulse.

electron pulse and disappeared completely after sereral usec.

The maximum optical density of the absorption in carbon dioxide was about 0.06 , but in carbon monoxide the optical density immediately after the pulse was about twice this value. We take this to mean that the yield of $\mathrm{C}\left({ }^{1} S\right)$ atoms in carbon monoxide is about twice that in carbon dioxide. At this stage it is not possible to discuss the nature or the kinetic order of the reactions of ( $\left({ }^{1} S\right)$ in pure carbon dioxide or monoxide. In view of the marked effect of small amounts of propylene, methane and hydrogen on the half-life of the transient, it is probable that in these cases $\mathrm{C}\left({ }^{1} S\right)$ atoms undergo rapid insertion or addition reactions as suggested by Wolfgang ${ }^{2}$. Dcactivation to a lower electronic state by a purely physical mechanism secms to be rather unlikely.

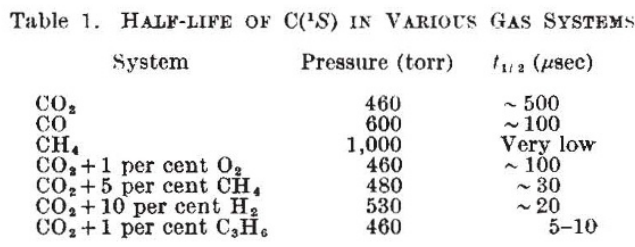

Further development of the experimental technique should enable absolute rate constants for many reactions involving $\mathrm{C}\left({ }^{1} S\right)$ atoms to be determined. Furthermore, careful analysis of products in, for example, carbon dioxideadditive systems may allow the primary yield of carbon atoms to be calculated. It should be borne in mind, however, that carbon atoms may also be produced initially in other low lying electronic states $\left({ }^{3} P\right.$ or $\left.{ }^{1} D\right)$ and react. with additives to give a similar product pattern.

\section{G. M. MeaburN \\ D. PERNER}

Service de Chimie Physique,

Centre d'Etudes Nucléaires de Saclay.

${ }^{1}$ Wolf. A. P., Adv. Phys. Org. Chem., 2, 245 (Academic Press Inc., Londom, 1964).

2 MacKay, C., and Wolfgang, R. L., Science, 148, 899 (1965). Wolfgang, R. L.. Prog. in Reaction Kinetics, 3 (Pergamon Press, Oxford, 1965). Rose, 'T'. MacKay, C., and Wolfgang, R. L., J. Amer. Chem. Soc., 88, 1064 (1966). Nicholas, J., MacKay, C., and Wolfgang, R. L., J. Amer. Chem. Soc., 88 1065 (1966).

${ }^{3}$ Szabo, Z., J. Amer. Chem. Soc., '72, 3497 (1950).

4 Stief, L. J., and De Carlo, V. J., J. Chem. Phys., 43, 2552 (1965).

5 Progress in Reaction Kinetics, 3, chapter 6 (Pergamon Press, Oxford, 1965).

- White, J. V., J. Opt. Soc. Amer., 32. 285 (1942). 